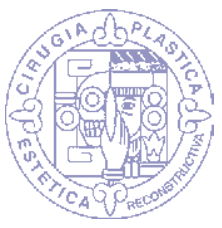

\title{
Seguridad en la aplicación de rellenos faciales. Medicina basada en evidencia
}

\author{
Safety in the application of facial dermal fillers. Evidence Based Medicine
}

\author{
Dra. Estela Vélez-Benítez, ${ }^{*}$ Dr. Jesús Cuenca-Pardo, ${ }^{\ddagger}$ \\ Dr. Guillermo Ramos-Gallardo, ${ }^{\ddagger}$ Dra. Karina Ramos-Ramos ${ }^{\S}$
}

Palabras clave: Rellenos faciales, seguridad, complicaciones, evento adverso.

Keywords: Dermal filler, safety, complications, adverse event.

\footnotetext{
* Integrante del Comité de Seguridad de la Asociación Mexicana de Cirugía Plástica, Estética y Reconstructiva, A.C.

¥ Asesor del Comité de Seguridad de la Asociación Mexicana de Cirugía Plástica, Estética y Reconstructiva, A.C. Coordinador del Comité de Seguridad de la FILACP.

$\S$ Dermatóloga. Centro Dermatológico Integral en La Paz.
}

Los autores de este artículo no tienen conflicto de intereses que declarar.

Recibido:

24 enero 2019 Aceptado para publicar: 04 marzo 2019

\section{RESUMEN}

La aplicación de rellenos faciales es uno de los procedimientos no quirúrgicos más utilizados en el consultorio para combatir la apariencia de la edad. Como en cualquier otro procedimiento cosmético inyectable, es probable que puedan ocurrir complicaciones, incluso en manos experimentadas. Por ello, es deber del cirujano plástico y dermatólogo lograr identificarlas de manera temprana y manejarlas adecuadamente: abscesos, celulitis, nódulos no inflamatorios y granulomas de cuerpos extraños son las complicaciones más comunes relacionadas con este procedimiento. A partir de esta perspectiva, el propósito del presente trabajo es realizar una revisión sistemática para establecer los lineamientos de seguridad, prevenir las complicaciones, describir las características de imagen de los rellenos faciales y las complicaciones relacionadas con éstos, y definir los problemas de interpretación y las condiciones dermatológicas que imitan las complicaciones relacionadas con el relleno facial.

\section{ABSTRACT}

The application of facial fillers is one of the non-surgical anti-aging procedures most frequently used in doctors' offices. As with any other injectable cosmetic procedure, complications are likely to occur even in experienced hands; however, it is the duty of the plastic surgeon and dermatologist to identify them early and handle them appropriately: abscess, cellulitis, non-inflammatory nodules and foreign body granulomas are the most common complications related to the filling. The purpose of this article is to carry out a systematic literature review, propose safety guidelines to prevent complications, describe the image characteristics of the facial fillers, the complications related to the filling, interpretation problems and skin conditions that resemble complications that have to do with the filling.

\section{METODOLOGÍA}

$\mathrm{U}$ n grupo multidisciplinario del Comité de Seguridad de la Asociación Mexicana de Cirugía Plástica y Reconstructiva se reunió para discutir el manejo de las complicaciones asociadas con el uso de rellenos dérmicos. A partir de ello, se realizó una búsqueda para su discusión de los artículos con metaanálisis, revisión y medicina basada en evidencias nivel I y II, tanto en inglés como en español, en MEDLINE y PubMed, mediante los términos de búsqueda «complicaciones»y «rellenos dérmicos».

\section{ESCENARIO}

Nuestro escenario fue a partir del caso de una mujer de 25 años edad, sin antecedentes de importancia, quien acudió por un aumento del volumen en los labios. Para ello, se aplicó un vial de ácido hialurónico mediante técnica antiséptica con clorhexidina, previa lidocaína local con aguja de $27 \mathrm{~mm}$ en el labio inferior, más la aplicación en vermellón lateral en la porción inferior del labio, con aspiración de la jeringa, y aplicación de $0.3 \mathrm{~mL}$ en cada lado.

Inmediatamente a este procedimiento, se observaron cambios de coloración violácea 
con aumento de volumen progresivo y dolor. Se inició tratamiento con aplicación de hielo local y compresión directa. Al siguiente día, continuó con cambios de coloración y aumento de volumen, por lo que se indicó masaje compresivo, esteroide con $8 \mathrm{mg}$ de dexametasona intramuscular cada 24 horas por tres días y fomentos de agua caliente. En una semana, hubo remisión del cuadro; la paciente manifestó conformidad estética.

Preguntas relacionadas con el tema de complicaciones de los rellenos faciales:

1. ¿Cuáles son las características de seguridad de los rellenos faciales?

2. ¿Cuáles son los diferentes tipos de rellenos faciales?

3. ¿Cuáles son los sitios de seguridad para la aplicación de rellenos faciales?

4. ¿En quiénes están contraindicados los rellenos faciales?

5. ¿Cómo determinar el riesgo de complicaciones en rellenos faciales?

6. ¿Cuándo se presentan las complicaciones de los rellenos faciales?

7. ¿Cómo se previenen las complicaciones?

8. ¿Cuáles son las principales complicaciones de los rellenos faciales?

9. ¿Cómo hago el diagnóstico?

10. ¿Cuál es el tratamiento de las complicaciones?

Algunas consideraciones útiles para el tratamiento de las complicaciones por rellenos faciales

- ¿Qué es la hialuronidasa (HYAL)?

- ¿Cómo utilizo la hialuronidasa (HYAL)?

- ¿Cuándo está indicada la antibioticoterapia?

- ¿Cuáles son las principales reacciones de hipersensibilidad?

\section{INTRODUCCIÓN}

Los rellenos faciales se utilizan para corregir las líneas de expresión, las depresiones congénitas o adquiridas de los tejidos blandos, los defectos postquirúrgicos y para el remplazo de volumen. ${ }^{1-4}$ Éstos se pueden recomendar como tratamiento para pacientes que buscan un rejuvenecimiento no invasivo; sin embargo, conforme más se usan, los eventos adversos aumentan. ${ }^{5}$

La Sociedad Americana de Cirujanos Plásticos (ASPS, por sus siglas en inglés) reporta que, en los Estados Unidos de Norteamérica, en 2018, los rellenos faciales fueron utilizados en 810,240 pacientes, ${ }^{6}$ lo que hace a este procedimiento no quirúrgico el segundo más frecuente, después de la aplicación de la toxina botulínica. ${ }^{2}$

\section{1. ¿Cuáles son las características de seguridad de los rellenos faciales?}

Deben tener las siguientes características: ser seguro, biocompatible, resistente a la infección, de fácil fijación al tejido, mantener su volumen, inducir una mínima reacción inflamatoria, no teratogénico, no carcinogénico y no alergénico, no requerir pruebas de sensibilidad previas a la aplicación, además de ser indoloro, barato y estable a temperatura ambiente. ${ }^{1,7}$

Recomendaciones (nivel de evidencia

\section{III, V; recomendación C-D):}

El relleno facial debe ser seguro para la paciente y debe cumplir con los requerimientos de seguridad referidos en el párrafo anterior. El médico tiene la obligación de conocer estos principios de bioseguridad.

\section{2. ¿Cuáles son los diferentes tipos de rellenos faciales?}

Se clasifican por sus propiedades, tiempo de biodegradación, composición (uno o más materiales) y naturaleza ${ }^{2}$ en:

- Autógenos: grasa del paciente.

- Biológicos: colágena bovina, porcina o humana, y ácido hialurónico (HA).

- Sintéticos: parafina, silicón, hidroxiapatita de calcio $(\mathrm{CHA})$, polimetilmetacrilato (PMMA), microesferas, hidrogel de poliacrilamida, metacrilato de hidroxietilo/etilo y ácido poli-L-láctico (PLLA), y policaprolactona-1 (PCL-1). ${ }^{1,2}$

Otra clasificación genérica los divide en dos clases principales: reversibles e irreversibles. ${ }^{8}$

Según las características de la biodegradación, también se dividen en: 
a) Temporales:

- Reabsorción rápida < 12 meses: HA y colágena.

- Reabsorción lenta < 24 meses: HA con perlas de dextrán, ácido poli-L-láctico, hidroxiapatita de calcio y policaprolactona-1 (PCL-1).

b) Permanentes: silicón, polimetilmetacrilato y poliacrilamidas. ${ }^{2,9,10}$

Los rellenos de HA son los más utilizados por su seguridad, y por sus mínimos efectos secundarios y reversibilidad. ${ }^{2}$ La duración depende del tamaño molecular y reticulación de 12 a 18 meses. Actualmente, existen aproximadamente 200 tipos de rellenos faciales en el mercado (Tabla 1). ${ }^{1,9}$

\section{3. ¿Cuáles son los sitios de seguridad para la aplicación de rellenos faciales?}

El cuerpo está dividido en bloques compuestos de múltiples tejidos, Ilamados angiosomas; cuando se presentan accidentes vasculares, tienden a afectar estas estructuras. ${ }^{11}$ Por un lado, la mayor parte del suministro de sangre a la cara es llevado a cabo a través de la arteria carótida externa. Por el otro, la región central (ojo, nariz y frente) está irrigada por la arteria oftálmica de la carótida interna, en sus ramificaciones: supraorbitaria, supratroclear, dorsal nasal y lagrimal, que se pueden afectar al inyectar la glabela, nariz y frente. ${ }^{3,5}$
Al considerar la colocación de rellenos en el área temporal, existen tres planos para la inyección segura: subcutánea, profunda a la fascia temporoparietal y profunda debajo del músculo temporal en el periostio. Los rellenos de HA se deben colocar en el plano subcutáneo o en la profundidad de la fascia temporoparietal. Los estimuladores de colágena, como el ácido poli-L-láctico o la hidroxiapatita de calcio, se deben colocar en la profundidad del músculo temporal, directamente en el periostio, para proporcionar un volumen seguro y duradero. ${ }^{3}$

Al evaluar el riesgo específico del sitio, los labios son los más propensos a desarrollar nódulos por la mucosa delgada, mayor cantidad de flora bacteriana y mayor movilidad de la región perioral. Con la inyección de hidroxiapatita de calcio, se suelen presentar nódulos; el HA está contraindicado en la mucosa labial. Los rellenos nunca deben inyectarse en el músculo, especialmente en el orbicular, debido a la mayor formación de nódulos. Los pacientes deben intentar minimizar el movimiento durante uno a tres días después del procedimiento. ${ }^{10}$

Recomendaciones (nivel de evidencia III-V; recomendación A):

1. Antes de infiltrar un relleno facial, se debe conocer la anatomía de la cara y los sitios de seguridad.

2. Algunos rellenos no deben aplicarse en ciertas regiones faciales porque pueden formar nódulos.

Tabla 1: Tipos de rellenos faciales.

\begin{tabular}{|c|c|c|c|c|c|}
\hline Componente & Policaprolactona & Hidroxiapatita & Ácido poliláctico & Ácido hialurónico & Colágena \\
\hline & Ellanse & Radiesse & Sculptra & $\begin{array}{l}\text { Restylene } \\
\text { Belotero } \\
\text { Filorga } \\
\quad \text { Art Filler } \\
\text { Juvederm } \\
\text { Elevess } \\
\text { Prevele } \\
\text { Hyalform } \\
\text { Perfectha }\end{array}$ & $\begin{array}{l}\text { Zyderm } \\
\text { Cosmoderm } \\
\text { Cosmoplast }\end{array}$ \\
\hline
\end{tabular}


3. Antes de infiltrar un relleno facial, se debe aspirar con la jeringa y estar seguro de que la aguja no se encuentra dentro de un vaso sanguíneo.

4. Infiltrar bolos en pequeñas cantidades y en diferentes sitios.

\section{4. ¿En quiénes están contraindicados los rellenos faciales?}

Se contraindican en aquellos pacientes con hipersensibilidad, trastornos hemorrágicos, alergias graves y antecedente de choque anafiláctico. El polimetilmetacrilato está contraindicado en la mucosa del labio. Este último, junto con el ácido poli-L-láctico, no se deben utilizar en pacientes con cicatrices queloides o hipertróficas. ${ }^{1}$

Recomendaciones (nivel de evidencia III; recomendación $\mathrm{A}$ ):

No usar rellenos en pacientes con hipersensibilidad, trastornos hemorrágicos, alergias graves y antecedente de choque anafiláctico.

\section{5. ¿Cómo determinar el riesgo de complicaciones en rellenos faciales?}

Es necesario realizar una historia clínica cuidadosa y completa del paciente, relacionada con: aplicaciones previas, síntomas potenciales del síndrome dismórfico, alergias, reacciones, enfermedades autoinmunes, tratamientos farmacológicos (particularmente inmunomoduladores), infecciones crónicas, enfermedades graves, y antecedentes familiares y genéticos. ${ }^{7,9}$

Recomendaciones (nivel de evidencia III, V; recomendación C-D):

1. Es indispensable la valoración antes del procedimiento.

2. Es necesaria la historia clínica completa.

3. Es obligatorio un consentimiento informado.

\section{6. ¿Cuándo se presentan complicaciones de los rellenos faciales?}

Las complicaciones tempranas relacionadas con el procedimiento y respuesta al material inyectado se presentan en menos de dos semanas, y éstas se manifiestan como eritema, hematomas, hipertermia, edema, hipersensi- bilidad, nódulos y protuberancias; las tardías se hacen evidentes de 14 días a un año y, las retrasadas, más de un año. Se pueden presentar en forma inmediata, hasta 24 horas después del procedimiento, mediatas de 24 horas a cuatro semanas y, retrasadas, después de más de cuatro semanas. . $^{2,8,9,11-13}$

\section{7. ¿Cómo se previenen las complicaciones?}

Se debe utilizar rellenos de marcas conocidas por su calidad, las cuales reportan una menor tasa de complicaciones. ${ }^{9}$ Es necesario conocer los compartimentos superficiales y profundos entre el SMAS y el periostio. ${ }^{14}$ La anatomía de la cara es compleja, con nervios y vasos que corren en planos delgados. Por ello, se requiere un conocimiento anatómico adecuado para evitar complicaciones graves; ${ }^{3}$ los errores técnicos están relacionados con la elección, ubicación y profundidad incorrectas de la colocación del producto y no con la cantidad utilizada. ${ }^{9}$

Se recomienda suspender temporalmente el uso o prescripción de los inmunomoduladores, analgésicos, antiinflamatorios y anticoagulantes antes del tratamiento, además, es preferible evitar el ejercicio intenso durante 24 horas y reinyecciones en la misma área para evitar la vasodilatación por lidocaína. ${ }^{1,15}$

La técnica empleada está asociada con el riesgo de complicaciones. La inyección rápida de grandes volúmenes producir disección del plano subepidérmico. ${ }^{8,15}$ Durante la aplicación se recomienda aspirar antes de inyectar, y aplicar lentamente con mínima presión en diferentes puntos con pequeños volúmenes (menos de 0.1 $\mathrm{mL}$ ), pues esto permite más control. Las agujas en movimiento se usan con precaución en áreas propensas a complicaciones vasculares; $y$ se recomienda usar cánulas romas. Al penetrar a un plano más profundo, es preferible utilizar calibre 22 y $70 \mathrm{~mm}$ de largo y evitar agujas pequeñas. ${ }^{15-17}$

La reducción de la infección está relacionada con una antisepsia cutánea efectiva, la cual se puede llevar a cabo con gluconato de clorhexidina al $2 \%$, el uso de guantes desechables y material estéril. ${ }^{15,16}$

Después de la aplicación del relleno, se debe evitar por 24 horas la exposición a cambios de temperatura, tocar o presionar el sitio de aplicación y evitar el contacto con el agua 
para que no se inflame; también, durante una semana, se debe evitar el consumo de alcohol y tabaco. $1,15,16$

\section{Recomendaciones (nivel de evidencia II;} recomendación B):

1. Se debe utilizar rellenos de marcas conocidas.

2. Es obligatorio conocer la anatomía facial y los angiosomas, así como el sitio de aplicación.

3. Los errores técnicos se presentan al escoger el plano incorrecto de la colocación y por la elección inadecuada del producto.

4. Se debe evitar la inyección rápida de grandes volúmenes.

5. Se recomienda la aspiración antes de aplicar el relleno.

6. Se debe evitar la exposición a cambios de temperatura, el consumo de alcohol y cigarro por una semana, y presionar el sitio de aplicación.

7. Es necesario suspender anticoagulantes y ejercicio intenso durante 24 horas y evitar las reinyecciones en las mismas áreas.

8. Se debe evitar la aplicación de bolos grandes; en contraste, se recomienda la aplicación lenta de pequeños volúmenes.

9. Se recomienda utilizar cánulas romas para la aplicación.

10. Se sugiere el uso de antisepsia cutánea efectiva con gluconato de clorhexidina al $2 \%$, así como guantes desechables y material estériles.

\section{8. ¿Cuáles son las principales complicaciones que se presentan?}

Las complicaciones más comunes son absceso, celulitis, nódulos no inflamatorios y granulomas y, las menos frecuentes, infección, lesión vascular y ceguera (Tabla 2).2,4

También se puede presentar edema, equimosis y eritema. Aparecen en el momento de la aplicación y se resuelven espontáneamente; si persisten, es probable que haya una reacción de hipersensibilidad. Los pacientes con rosácea tienen mayor riesgo. ${ }^{1}$

Los nódulos suelen ser muy frecuentes; los inflamatorios pueden aparecer de días a años y los no inflamatorios después de la aplicación. Se relacionan con la colocación incorrecta. ${ }^{13}$ Por su presentación pueden ser quísticos, edematosos y esclerosantes; son palpables, bien delimitados en el sitio de inyección y

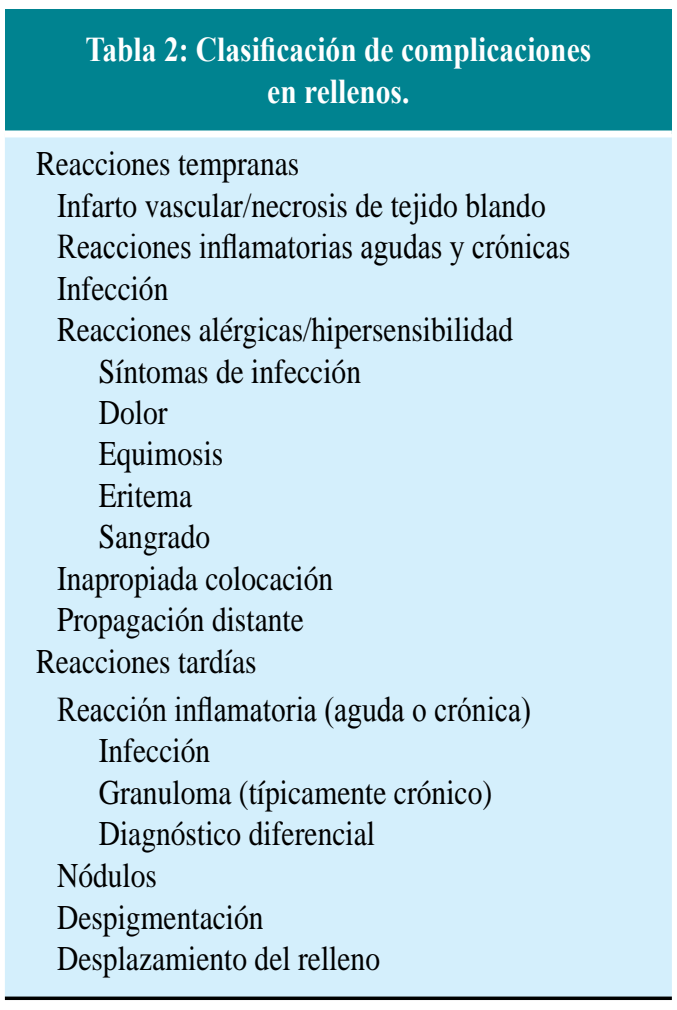

son causados por la aplicación de abundante material y acumulación o desplazamiento por el movimiento de los músculos. ${ }^{15}$

La presencia de infección es rara $(<0.2 \%)$ por asepsia inadecuada de la piel. Se relaciona con las bacterias Staphylococcus epidermidis, Propionibacterium acnes y micobacterias no tuberculosas (MNT); su presentación es de 3 a 6 semanas $^{2}$ y pueden formar un absceso.

La migración puede ser resultado del desplazamiento del relleno por los músculos o la gravedad, en planos superficiales o áreas anatómicas móviles como los labios. ${ }^{1}$

La presencia de granulomas es debido a que el relleno encapsulado puede resistir la degradación y permanecer secuestrado en los macrófagos, secretando citoquinas que atraen a otros macrófagos y aumentan su tamaño, o pueden fusionarse formando un granuloma con criterio histopatológico a diferencia del nódulo. La frecuencia es del 0.01 al 1\%, y se presentan con todos los rellenos después de meses a años; sin embargo, se reporta una alta incidencia con policaprolactona, ${ }^{9}$ como nódulos rojos inflamados con cultivo negativo. ${ }^{1,16}$ 
El biofilm es una acumulación de microorganismos adherentes entre sí, con una variedad de superficies; las bacterias pueden evitar la reacción autoinmune, por lo que los antibióticos no tienen efecto. ${ }^{18}$

También puede hacerse ostensivo el infarto vascular y necrosis. Éstas constituyen una de las complicaciones más severas, y se puede presentar en la fase inmediata por embolismo intravascular del material inyectado, por lesión directa de la aguja o por compresión externa de los vasos por las propiedades hidrófilas del producto. $^{1}$

Una de las complicaciones más devastadoras es la necrosis cutánea localizada o pérdida permanente de la visión por compromiso de la arteria oftálmica. La lesión de la arteria de la retina puede causar oclusión vascular. ${ }^{8,16}$ La embolización arterial es usualmente anterógrada con oclusión directa de una arteria, causando isquemia distal al punto de inyección. El flujo retrógrado del relleno contra la presión arterial, seguido de un flujo anterógrado a través de la rama arterial, provoca embolia medicamentosa (síndrome de Freudenthal-Nicolau). ${ }^{17}$

Por su naturaleza vascular, la glabela es el sitio más frecuente de necrosis causada por la inyección intrarterial, 16,17,19 seguido de la región nasal, el pliegue nasolabial y la frente. Las inyecciones involuntarias de la arteria nasal, supratroclear, angular y dorsal pueden provocar isquemia y necrosis. ${ }^{1,20} \mathrm{La}$ mayoría de los casos son por infiltración de grasa, seguida del ácido hialurónico, $y^{5}$ clínicamente, se manifiestan con dolor y palidez isquémica; ${ }^{5,16}$ los cambios inmediatos son blanqueamiento, cambios de coloración, dolor (excepto que presente bloqueo nervioso o anestesia local), Ilenado capilar lento o ausente, pérdida de la función y, finalmente, necrosis de la piel. ${ }^{1}$ Una oclusión venosa se presenta con un moteado venoso denominado livedo reticularis. ${ }^{16}$

\section{9. ¿Cómo hago el diagnóstico?}

En la mayoría de los casos, los rellenos faciales inyectables se detectan de forma incidental en los estudios de imagen de corte transversal. La resonancia magnética (RM) o ultrasonido de alta definición pueden detectar la ubicación y el volumen de los rellenos faciales inyectados, además de evaluar las complicaciones relacionadas. La RM se prefiere sobre el ultrasonido, al proporcionar referencia anatómica; la tomografía, por su parte, no ofrece ventajas sobre la RM. ${ }^{2,21}$ La parafina como relleno facial causa reacciones granulomatosas graves y «formación de parafinoma». Las características de la tomografía computarizada para «parafinoma» incluyen focos redondeados y nódulos de densidad de tejidos blandos con un borde calcificado. $^{2}$

\section{Recomendaciones (nivel de evidencia I-III; recomendación A-B):}

1. Para localizar la ubicación y el volumen de los rellenos faciales inyectados, es necesario evaluar las complicaciones relacionadas por medio de la resonancia magnética o el ultrasonido de alta definición.

2. La resonancia magnética proporciona referencias anatómicas.

3. La tomografía computarizada no ofrece ventajas.

\section{0. ¿Cuál es el tratamiento de las complicaciones?}

El tratamiento depende de la gravedad; con frecuencia, se puede autolimitar y resolver espontáneamente en horas o días. Algunos casos, se requiere de tratamiento local y sistémico. La naturaleza de la complicación se clasifica en ligera y ésta desaparecer por sí misma, suele ser moderada y requerir sólo tratamiento, o severa y que requiera intervención inmediata. ${ }^{2,9}$

El edema, equimosis y eritema se resuelven espontáneamente con frío, masaje y antihistamínicos; si persisten durante varios días, es necesario el uso de esteroide y vitamina $\mathrm{K}^{1}{ }^{1}$

Para evitar los nódulos, granulomas y migración, se recomienda colocar en plano profundo y dar masaje firme. Aquellos relacionados con ácido poliláctico son más persistentes, difíciles de tratar y responden a esteroides intralesionales. El manejo del nódulo tipo quístico es por medio de incisión y drenaje. Los esteroides son menos efectivos para la hidroxiapatita de calcio. $^{22}$

Los casos complicados con procesos infecciosos requieren cultivos, biopsia y tratamiento 
específico. ${ }^{1,8,15}$ En caso de absceso fluctuante, se requiere realizar incisión y drenaje. Si no fluctúa, se recomienda antibióticos y esteroides. La hialuronidasa no se debe usar por el riesgo de propagación de la infección. Si estos tratamientos fallan, se debe sospechar de formación de biofilm por Staphylococcus aureus resistente a la meticilina (SARM) o tuberculosis atípica (TB). 1,8 Una vez desaparecidos los signos de infección, la hialuronidasa se puede utilizar para disminuir la fibrosis; ${ }^{15,23}$ ésta ayuda a descomponer la matriz del biofilm y disminuye su tamaño. Otras opciones son antibioticoterapia prolongada, administración de 5-FU intralesional y láser intralesional. 1,8,16,24 La preparación quirúrgica y una buena técnica estéril pueden reducir su incidencia. ${ }^{8}$

Ante la sospecha de necrosis, se debe iniciar el tratamiento inmediatamente, interrumpir la inyección y aplicar presión y masaje en el área, además de compresas tibias o calientes para aumentar la vasodilatación. El objetivo del tratamiento es disolver el producto, para que se facilite el flujo sanguíneo y se promueva la vasodilatación. La nitroglicerina tópica al 1\%, hialuronidasa, aspirina y esteroides sistémicos o tópicos ayudan a reducir la inflamación y el grado de lesión; 1,8,15,16 sin embargo, algunos autores mencionan que la nitroglicerina puede empeorar la isquemia.

La aspirina, prostaglandinas intravenosas, eliminación del relleno por punción y heparina de bajo peso molecular no han demostrado su eficacia hasta el momento. ${ }^{1,16}$ Algunos autores recomiendan el uso de hialuronidasa en todos los casos de compromiso vascular, independientemente del tipo de relleno, pues reduce el edema y la presión del vaso ocluido. Después del tratamiento inicial, si persiste la isquemia, se sugiere la administración del oxígeno hiperbárico; no obstante, no hay evidencias suficientemente fuertes que apoyen esta recomendación. ${ }^{11}$ En caso de necrosis, se requiere desbridamiento y reconstrucción con injerto de piel o cartílago y colgajo local. ${ }^{1,15}$

Para el infarto intravascular, se recomienda un mínimo de 200 a 300 unidades de hialuronidasa por día en toda el área necrosada, por un mínimo de dos días hasta que aparezcan signos de flujo sanguíneo y, de ser necesario, se recomiendan hasta 1,500 unidades.
El paciente debe ser reevaluado cada 24 horas. Si surge alguna infección, la terapia con antibióticos es la elección. En casos de ceguera, existe incertidumbre del tratamiento, sin embargo, se recomienda la inyección inmediata de hialuronidasa. ${ }^{23,25}$

Las medidas para mejorar la perfusión retiniana descritas con resultado limitado incluyen la consulta oftalmológica inmediata, masaje ocular, gotas oftálmicas con timolol, terapia hiperbárica, diuréticos, corticosteroides sistémicos y tópicos, anticoagulación y descompresión de la cámara anterior. ${ }^{15,21}$

Las reacciones tardías se resuelven incluso con esteroides orales. ${ }^{16}$ La luz pulsada está indicada en el tratamiento de cicatriz hipertrófica y telangiectasias. ${ }^{1}$

Recomendaciones (nivel de evidencia III, $\mathrm{V}$; recomendación $\mathrm{A}-\mathrm{B})$ :

1. El tratamiento depende de la gravedad. Frecuentemente se puede autolimitar y resolver espontáneamente.

2. El edema, equimosis y eritema se resuelven espontáneamente con frío, masaje y antihistamínicos.

3. En caso de infección o absceso fluctuante, se necesita cultivo, antibióticos, incisión y drenaje. Si no fluctúa, se recomienda antibióticos y esteroides. En la etapa inicial, la hialuronidasa no se debe usar por el riesgo de propagación.

4. Ante el diagnóstico de necrosis, el tratamiento es inmediato.

5. Para el infarto intravascular, se recomienda un mínimo de 200 a 300 unidades de hialuronidasa por día en toda el área necrosada, mínimo por dos días hasta que aparezcan signos de flujo sanguíneo; de ser necesario, se recomiendan hasta 1,500 unidades.

6. Es necesario contar con un equipo emergente en el consultorio (Tabla 3).

Algunas consideraciones útiles en el tratamiento de las complicaciones por rellenos faciales.

\section{¿Qué es la hialuronidasa (HYAL)?}

Es una enzima mucolítica que hidroliza los rellenos dérmicos naturales y reticulados de 
Tabla 3: Componentes del equipo de manejo de complicaciones de rellenos de ácido hialurónico.

Hialuronidasa

Esteroides: oral e intralesional

Antibióticos

Antivirales

Nitroglicerina tópica al 1\%

Antihistamínicos

Aspirina: 325 mg, vía oral

Compresas calientes

Teléfono de urgencias de oftalmólogo y

oxígeno hiperbárico

HA, y constituye el estándar de oro para el tratamiento de las complicaciones asociadas con el relleno de HA. 6,26

Existen tres grupos principales de efectos adversos por rellenos de HA que se tratan con hialuronidasa: la aplicación excesiva o superficial, los nódulos y las oclusiones vasculares. ${ }^{23}$

\section{¿Cómo utilizo la hialuronidasa (HYAL)?}

Se recomienda $0.08 \mathrm{~mL}$ de cada producto, con 16 unidades de hialuronidasa y una degradación de un $90 \%$ en las primeras seis horas. El lavado del tejido isquémico con hialuronidasa puede sustituir la inyección intravascular directa en la mayoría de los casos. ${ }^{23}$ La dosificación de hialuronidasa por región de aplicación es en piel, nasal y perioral, de 15 a 30 unidades; en el área periorbitaria, de 30 unidades; en el área infraorbitaria, de 10 a 15 unidades, y en el párpado inferior, de 1.5 unidades. $^{27}$

\section{Recomendaciones para el uso de la hialuronidasa}

- En área menor de $2.5 \mathrm{~mm}$, se recomienda una inyección simple de 10 a 20 unidades.

- En un área de $2.5 \mathrm{~mm}$ a $1 \mathrm{~cm}$, de 2 a 4 puntos de inyección con 10 a 20 unidades por punto de inyección.

- Las inyecciones se pueden repetir diariamente por lo menos cuatro días. ${ }^{28}$

Los diferentes geles de HA difieren en su sensibilidad a la hialuronidasa. Se considera usar dosis más altas para rellenos más resistentes y en situaciones de emergencia. ${ }^{23}$ Existe la posibilidad de reacciones de hipersensibilidad graves a la hialuronidasa, pero hasta ahora no se han reportado. ${ }^{23,28}$

Recomendaciones (nivel de evidencia I- IV; recomendación A):

1. La dosis recomendada es de $0.08 \mathrm{~mL}$ de cada producto con 16 unidades de hialuronidasa, con una degradación de más del $90 \%$ dentro de las seis primeras horas de la exposición.

2. Los geles HA difieren en su sensibilidad a la hialuronidasa. En estos casos, se considera el uso de dosis más altas para rellenos más resistentes y para situaciones de emergencia. ${ }^{23}$

\section{¿Cuándo está recomendada la antibioticoterapia?}

Se recomienda antibioticoterapia empírica inicial, seguida de una reevaluación con biopsia y cultivo si no hay mejoría. Se indica $500 \mathrm{mg}$ de claritromicina más 400 mg de moxifloxacino dos veces al día durante 10 días, o 500 a 750 mg de ciprofloxacina dos veces al día durante dos a cuatro semanas, o $100 \mathrm{mg}$ de minociclina una vez al día durante seis meses. ${ }^{15}$

En infecciones agudas tempranas, se recomienda dar amoxicilina más clavulanato, cefalexina, o ciprofloxacina, y continuar con hialuronidasa y esteroides. En infecciones crónicas tardías, se indica la siguiente secuencia: antibióticos (empíricos) cefalosporina de tercera o cuarta generación (cefixima), hialuronidasa y esteroides. ${ }^{15}$

Para evitar brotes herpéticos recurrentes, se recomienda profilaxis antiviral en pacientes con herpes y ésta debe retrasarse hasta la resolución completa. $^{15}$

En casos de Staphylococcus aureus resistente a la meticilina (SARM) o tuberculosis atípica (TB), ${ }^{1,8}$ se recomienda cultivo del material infectado, prueba de TB, quinolonas, macrólidos o cefalosporinas de tercera generación, hialuronidasa, 5-FU y, al final, la resección. 1,16

Recomendaciones (nivel de evidencia III-V; recomendación A-C):

1. Se recomienda antibioticoterapia empírica inicial. 
2. Se indican $500 \mathrm{mg}$ de claritromicina más $400 \mathrm{mg}$ de moxifloxacino dos veces al día durante 10 días, o de 500 a 750 mg de ciprofloxacina dos veces al día durante dos a cuatro semanas, o $100 \mathrm{mg}$ de minociclina una vez al día durante seis meses.

3. Para infecciones agudas tempranas, se recomienda amoxicilina más clavulanato, cefalexina, o ciprofloxacina y continuar con hialuronidasa y esteroides.

4. En infecciones crónicas tardías, se sugiere una secuencia de antibióticos (empíricos), cefalosporina de tercera o cuarta generación (cefixima), hialuronidasa y esteroides.

¿Cuáles son las principales reacciones de hipersensibilidad?

Las principales reacciones de hipersensibilidad se relacionan con la contaminación microbiana; para este tipo de reacciones, se recomienda antibioterapia de amplio espectro, AINE y evitar esteroides. ${ }^{24}$

Desde una perspectiva inmunológica, los rellenos actúan como adyuvantes en lugar de activadores directos de células $T$, con una predisposición genética. El manejo de las reacciones agudas y sistémicas suele ser difícil, requiriendo terapia antiinflamatoria e inmunosupresora. ${ }^{13}$

El angioedema que progresa se debe considerar una emergencia, debido a una posible obstrucción de la vía aérea. ${ }^{15}$ Inicialmente, se presentaron hipersensibilidad y granulomas con $\mathrm{HA}$, sin embargo, ahora son raros (erupción multiforme y anafilaxia). Cuando se aplica muy superficial, se presenta el efecto Tyndall con una decoloración "azulada"; suelen ser de corta duración y responden a la hialuronidasa. 8,9,29

Recomendaciones (nivel de evidencia I, III-V; recomendación A-B):

En reacciones alérgicas o de hipersensibilidad, se recomienda una antibioterapia de amplio espectro y evitar los esteroides y AINES.

\section{DISCUSIÓN}

El Comité de Seguridad es el responsable de emitir la información sobre los rellenos y sus complicaciones, la cual puede ayudar a los médicos a evitar y tratar con éxito los posibles eventos adversos.
La inyección de relleno para el aumento de tejidos blandos es un procedimiento satisfactorio con resultados muy modestos, a pesar de las altas expectativas. Sin embargo, a medida que aumenta el número de indicaciones y el rendimiento, también aumenta el número de complicaciones.

Por un lado, es importante que los médicos conozcan la anatomía facial y las zonas de alto riesgo. Por el otro, la experiencia insuficiente es un factor que contribuye al desarrollo de complicaciones. El médico que inyecta el relleno debe tener experiencia, pues con ello se evitarán errores graves en el lugar de la inyección, el volumen, la velocidad y la profundidad, así como el tratamiento posterior a la ésta. El médico debe estar disponible después de la inyección y nunca desestimar las preocupaciones de un paciente. ${ }^{9}$

La técnica y selección adecuada de productos son importantes, puesto que también con ello se minimizan las reacciones adversas. Asimismo, contribuyen al mismo fin el conocimiento profundo de la anatomía y de una historia clínica completa que incluya antecedentes de contraindicaciones relativas o absolutas y los cambios postquirúrgicos, por ejemplo, rinoplastia, donde la gran mayoría de los casos presentan un cambio en la vascularización y fibrosis de ciertas áreas. 4,8,15,30,31

La arteria oftálmica se asocia significativamente con ceguera irreversible. En este sentido, la ceguera unilateral es el evento adverso vascular más frecuente; la grasa autóloga tiende a causar más casos de daño vascular permanente. ${ }^{19,20,32,33}$

Las precauciones para evitar una lesión intravascular, de acuerdo con el consenso del Global Aesthetic, incluyen la aspiración antes de la inyección, la inyección lenta con presión mínima y el suministro de material en diferentes puntos y en pequeños volúmenes por vez. También hace valer la importancia de mantener la aguja en movimiento. Algunos autores suelen recomendar el uso de agujas pequeñas, así como las microcánulas romas. ${ }^{15}$

Tratar a un paciente con empatía evita muchas demandas legales. ${ }^{9}$ La pronta identificación y el tratamiento correcto permiten la resolución exitosa de los síntomas inflamatorios en pocos días. ${ }^{34}$ Respecto a la seguridad, la técnica del médico es lo más importante. ${ }^{1}$ 


\section{CONCLUSIONES}

Los médicos deben ser plenamente conscientes y estar preparados frente a los signos y síntomas relacionados con las complicaciones que se presentan en los pacientes, para que, de esta manera, puedan sentirse tratados con confianza. El establecimiento de protocolos de acción para emergencias con agentes fácilmente disponibles en la oficina reduciría la gravedad de los resultados adversos asociados con la inyección de rellenos de ácido hialurónico en el entorno cosmético.

Este documento busca establecer un conjunto de recomendaciones e identificar los problemas clave que pueden ser útiles para los médicos que están comenzando a usar rellenos dérmicos. Además, intenta proporcionar una mejor comprensión sobre los diagnósticos y el manejo de las complicaciones si llegaran a ocurrir.

Una última recomendación, pero no por ello igual de importante: productos baratos no probados nunca deben ser utilizados.

\section{REFERENCIAS}

1. Joo Hyun Kim, Duk Kyun Ahn, Hii Sun Jeong, and In Suck Suh. Treatment algorithm of complications after filler injection: based on wound healing process. J Korean Med Sci 2014; 29 (3): 176-182.

2. Mundada P, Kohler R, Boudabbous S, Toutous Trellu L, Platon A. Injectable facial fillers: imaging features, complications, and diagnostic pitfalls at MRI and PET CT. Insights Imaging 2017; 8 (6): 557-572.

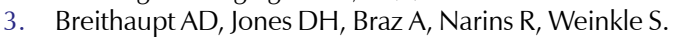
Anatomical basis for safe and effective volumization of the temple. Dermatol Surg 2015 Dec; 41, 1: S278-83

4. Bruna Souza FB, Gonçalves Bravo L, Da Rocha CM, Bianco de Souza S, Lopes FL. Evaluation and Proportion in Nasal Filling with Hyaluronic Acid. J Clin Aesthet Dermatol 2018; 11 (4): 36-40.

5. Beleznay K, Carruthers JD, Humphrey S, Jones D. Avoiding and treating blindness from fillers: A review of the World Literature. Dermatol Surg 2015; 41 (10): 1097-117.

6. The American Society for Aesthetic Plastic Surgery. Cosmetic (Aesthetic) Surgery National Data Bank. The American Society for Aesthetic Plastic Surgery, 2018. Disponible en: https: //www.surgery.org/sites/default/ files/ASAPS-Stats2018_0.pdf

7. Urdiales-Gálvez F, Dēlgado NE, Figueiredo V, LajoPlaza JV, Mira M. Preventing the Complications Associated with the Use of Dermal Fillers in Facial Aesthetic Procedures: An Expert Group Consensus Report. Aesthetic Plast Surg 2017; 41 (3): 667-677.

8. DeLorenzi C. Complications of injectable fillers, part 2: vascular complications. Aesthet Surg J 2014; 34 (4): 584-600.
9. Haneke Eckart. Adverse Effects of Fillers and Their Histopathology. Facial Plast Surg 2014; 30: 599-614.

10. Ledon JA, Savas JA, Yang S, Franca K, Camacho I, Nouri K. Inflammatory nodules following soft tissue filler use: a review of causative agents, pathology and treatment options. Am J Clin Dermatol 2013; 14 (5): 401-11.

11. Rohrich RJ, Nguyen AT, Kenkel JM. Lexicon for soft tissue implants. Dermatol Surg 2009; 35 (Suppl 2): 1605-1611.

12. Urdiales-Galvez F, Delgado NE, Figueiredo V, LajoPlaza JV, Mira M. Treatment of Soft Tissue Filler Complications: Expert Consensus Recommendations. Aesthetic Plast Surg 2018 Apr; 42 (2): 498-510

13. Alijotas-Reig J, Fernandez-Figueras MT, Puig L. Inflammatory, immune- mediated adverse reactions related to soft tissue dermal fillers. Semin Arthritis Rheum 2013; 43 (2): 241-58.

14. Rohrich RJ, Pessa JE. The fat compartments of the face: anatomy and clinical implications for cosmetic surgery. Plast Reconstr Surg 2007; 119 (7): 2219-2227.

15. Signorini $M$, Liew $S$, Sundaram $H$, De Boulle $K L$, Goodman GJ, Monheit G, Wu Y, Trindade de Almeida AR, Swift A, Vieira Braz A; Global Aesthetics Consensus Group. Global Aesthetics Consensus: Avoidance and Management of Complications from Hyaluronic Acid Fillers-Evidence- and Opinion-Based Review and Consensus Recommendations. Plast Reconstr Surg 2016; 137 (6): 961e-71e.

16. Woodward J. Facial Filler Complications. Facial Plast Surg Clin North Am 2015; 23 (4): 447-58.

17. Dayan SH. Complications from toxins and fillers in the dermatology clinic: recognition, prevention, and treatment. Facial Plast Surg Clin North Am 2013; 21 (4): 663-73.

18. Ibrahim O, Overman J, Arndt KA, Dover JS. Filler Nodules: Inflammatory or Infectious? A Review of Biofilms and Their Implications on Clinical Practice. Dermatol Surg 2018; 44 (1): 53-60.

19. Sito G, Manzoni V, Sommariva R. Vascular Complications after Facial Filler Injection: A Literature Review and Meta-analysis. J Clin Aesthet Dermatol 2019; 12 (6): E65-E72.

20. Thanasarnaksorn W, Cotofana S, Rudolph C, Kraisak P, Chanasumon N, Suwanchinda A. Severe vision loss caused by cosmetic filler augmentation: Case series with review of cause and therapy. J Cosmet Dermatol 2018; 17 (5): 712-718.

21. Ginat DT, Schatz CJ. Imaging Features of Midface Injectable Fillers and Associated Complications. Am J Neuroradiol 2013, 34 (8): 1488-1495.

22. Kadouch JA. Calcium hydroxyapatite: A review on safety and complications. J Cosmet Dermatol 2017; 16 (2): 152-161.

23. Landau M. Hyaluronidase Caveats in Treating Filler Complications. Dermatol Surg 2015; 41 (Suppl 1): S347-53.

24. Dumitraşcu DI, Georgescu AV Clujul Med. The management of biofilm formation after hyaluronic acid gel filler injections: a review. Clujul Medical (1957) [05 Aug 2013, 86 (3): 192-195].

25. Buhren BA, Schrumpf H, Bölke E, Kammers K, Gerber PA. Standardized in vitro analysis of the degradability of hyaluronic acid fillers by hyaluronidase. Eur J Med Res 2018; 23 (1): 37. 
26. Cavallini M, Gazzola R, Metalla M, Vaienti L. The role of hyaluronidase in the treatment of complications from hyaluronic acid dermal fillers. Aesthet Surg $J$ 2013; 33 (8): 1167-74.

27. Buhren BA, Schrumpf H, Hoff NP, Bölke E, Hilton S, Gerber PA. Hyaluronidase: from clinical applications to molecular and cellular mechanisms. Eur J Med Res 2016; 21: 5

28. Rayess HM, Svider PF, Hanba C, Patel VS, Dejoseph LM, Carron M, Zuliani GF. A Cross-sectional Analysis of Adverse Events and Litigation for Injectable Fillers. JAMA Facial Plast Surg 2018; 20 (3): 207-214.

29. Haneke E. Adverse effects of fillers. Dermatol Ther 2019; 32 (2): e12676.

30. Robati RM, Moeineddin F, Almasi-Nasrabadi M. The Risk of Skin Necrosis Following Hyaluronic Acid Filler Injection in Patients with a History of Cosmetic Rhinoplasty. Aesthet Surg J 2018; 38 (8): 883-888.

31. Bertossi D, Giampaoli G, Verner I, Pirayesh A, Nocini $R$, Nocini P. Complications and management after a nonsurgical rhinoplasty: A literature review. Dermatol Ther 2019; 32 (4): e12978.

32. Fitzgerald R, Bertucci V, Sykes JM, Duplechain JK. Adverse Reactions to Injectable Fillers. Facial Plast Surg 2016; 32 (5): 532-55.

33. Murthy R, Roos JCP, Goldberg RA. Periocular hyaluronic acid fillers: applications, implications, complications. Curr Opin Ophthalmol 2019; 30 (5): 395-400.

34. Bhojani-Lynch T. Late-Onset Inflammatory Response to Hyaluronic Acid Dermal Fillers. Plast Reconstr Surg Glob Open 2017; 5 (12): e1532.

Correspondencia:

Dra. Estela Vélez Benítez

Flamencos Núm. 74,

Col. San José Insurgentes,

Alcaldía Benito Juárez, 03900,

Ciudad de México, México.

E-mail: cirugiaplastica@draestelavelez.com 